\title{
SEPARAÇÃO GRANULOMÉTRICA DE NANOPARTÍCULAS DE PRATA POR CENTRIFUGAÇÃO.
}

\author{
W. F. de SOUSA, C. A. dos SANTOS e M. M. SECKLER
}

Universidade de São Paulo, Departamento de Engenharia Química da Escola Politécnica

E-mail para contato: waltersousa88@gmail.com

\begin{abstract}
RESUMO - Nanopartículas de prata (AgNPs) vêm ganhando importância na prevenção contra infecções, principalmente pela sua incorporação em dispositivos médicos, tecidos e outros produtos relacionados. Estudos prévios indicaram que AgNPs de menores tamanhos têm ação biocida mais efetiva (Martinéz-Castañón, G. A. et al., 2008). Nesse contexto, a centrifugação foi escolhida, entre outros métodos de separação granulométrica, por sua possibilidade de ressuspensão das AgNPs após a separação, pela facilidade do aumento de escala e pela simplicidade. Um modelo de perfil de concentração de AgNP na cela em função do tempo de centrifugação foi proposto a partir da Equação de Lamm (Behlke, J; Ristau, O., 1997), considerando a difusividade Browniana e o coeficiente Svedberg calculado a partir do balanço de forças. A equação foi resolvida com solução analítica proposta por Fujita (1962). O modelo mostrou que o movimento Browniano retarda a sedimentação, mas não impede a separação. Esta previsão foi comprovada experimentalmente pela separação completa de nanopartículas de prata com dimensões entre 2 e $50 \mathrm{~nm}$.
\end{abstract}

\section{INTRODUÇÃO}

Nanopartículas de prata (AgNPs) têm atraído muita atenção nos últimos anos por suas diversas aplicações, entre elas a ação antimicrobiana. Esta vem ganhando particular importância por ser muito mais efetiva em termos de concentração mínima inibitória do que seus homólogos iônicos (Santos, C. A. et al., 2012), de forma que sua incorporação em dispositivos médicos, tecidos e outros produtos relacionados à saúde tem possibilitado um maior controle preventivo contra infecções. Acredita-se que os microorganismos são menos propensos a desenvolver resistência às AgNPs em comparação aos antibióticos convencionais, isso ocorre porque metais em escala nanométrica atuam em diversos estágios vitais de bactérias e vírus, requerendo diversas mutações consecutivas para o desenvolvimento de resistência sobre eles (Backer, C. et al., 2005). Estudos recentes apontam que partículas de menores tamanhos tornam o poder antimicrobiano ainda maior. Nesse contexto, AgNPs ainda mais efetivas poderão ser obtidas com o desenvolvimento de processos pós-síntese que controlem melhor a concentração e tamanho das partículas.

Diversos métodos de separação granulométrica têm sido empregados para nanopartículas, cujas principais características são apresentadas na TABELA 1. Critérios como a possibilidade de aumento de escala do processo, a possibilidade de ressuspender as nanopartículas após a separação e a baixa 
complexidade do método (assinalados na tabela como + quando possíveis e - quando não) foram julgados importantes na seleção do método visando o objetivo proposto. Assim sendo, neste trabalho foi selecionado o método da centrifugação.

Tabela 1 - Comparação dos Métodos de Separação.

\begin{tabular}{ccccc}
\hline Método de Separação & Formato & Ressuspensão & $\begin{array}{c}\text { Aumento } \\
\text { de } \\
\text { Escala }\end{array}$ & Complexidade \\
\hline Eletroforese & + & + & - & Alta \\
"Field Flow Fractionation" & - & + & + & Alta \\
Métodos Cromatográficos & - & - & - & Média \\
Centrifugação & + & + & + & Média \\
\hline
\end{tabular}

Pode-se observar que na maioria dos casos a escala nanométrica está fora do domínio nos processos de separação convencionais de Engenharia Química. A partir disso, nesse trabalho busca-se estender o conhecimento sobre o mesmo em prol do seu grande potencial de uso na área médica. A centrifugação foi estudada teórica e experimentalmente.

\section{MODELO DE SEDIMENTAÇÃO DE NANOPARTÍCULAS SOB AÇÃO DA FORÇA CENTRÍFUGA}

A sedimentação de AgNPs em solução aquosa sob ação da força centrífuga foi analisada teoricamente a partir da Equação de Lamm, considerando a difusividade Browniana e o coeficiente de Svedberg calculado a partir do balanço de forças na partícula. Com uma solução analítica proposta por Fujita (1962), foi possível estabelecer parâmetros do processo de separação como velocidade de rotação e tempo de centrifugação. O desempenho da centrifugação foi avaliado analisando-se as partículas do sobrenadante em diversos tempos e velocidades de rotação.

\subsection{Abordagem e Premissas}

Primeiramente foi estimado número Knudsen (relação da dimensão da partícula com livre caminho médio) em função de diferentes dimensões de AgNPs. Este adimensional guia o tipo de abordagem dada ao problema: se podemos considerar o fluido como meio contínuo (mecânica dos meios contínuos, equações de Navier-Stokes, funções contínuas) ou se sua dimensão é tão pequena que ele deve ser tratado de forma discreta, em nível molecular (mecânica estatística, teoria cinética dos gases, funções discretas) (Friedlander, S. K., 2000). A TABELA 2 nos mostra esses resultados para AgNPs em meio aquoso a temperatura ambiente $\left(20^{\circ} \mathrm{C}\right)$ : 
Tabela 2 - Número de Knudsen

\begin{tabular}{cc}
\hline$D p(\mathrm{~nm})$ & $K n$ \\
\hline 1 & 0,0113 \\
10 & 0,004 \\
100 & 0,0012 \\
\hline
\end{tabular}

$$
K n=\frac{2 \lambda}{D_{p}}
$$

Kn - Número de Knudsen

$D p$ - Diâmetro da Partícula

$\lambda$ - Livre Caminho Médio

Como o número de Knudsen tende a zero mesmo para as menores partículas, o fluido pode ser tratado como meio contínuo. Sendo assim, propõe-se um balanço de forças (FIGURA 1) de uma partícula sob ação de campo externo com algumas premissas importantes: a partícula é considerada esférica e isolada (meio bastante diluído). A figura mostra a secção de uma cela centrífuga que gira conforme indicado pela seta.

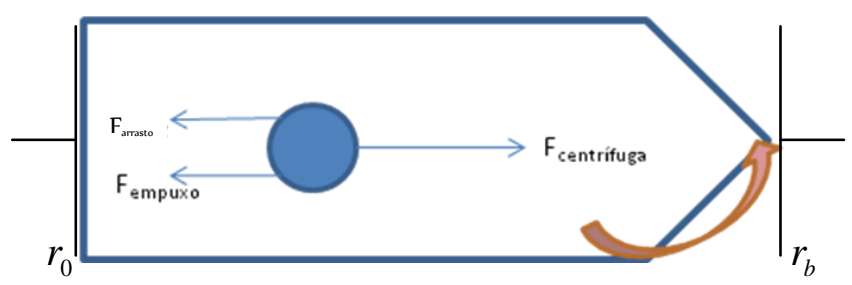

Figura 1 - Balanço de Forças de uma partícula sob ação de força externa.

Onde no equilíbrio: $F_{\text {arrasto }}+F_{\text {empuxo }}+F_{\text {centrifuga }}=0$

Sendo: $\quad F_{\text {centrifuga }}=m w^{2} r \quad F_{\text {arrasto }}=\frac{3 \pi \mu D_{p} v}{C_{c}} \quad F_{\text {empuxo }}=m_{0} w^{2} r$

Substituindo-se (2) em (1), chegamos ao seguinte valor da velocidade de sedimentação:

$$
\begin{array}{|c|c}
V=\frac{w^{2} r\left(m-m_{o}\right)}{3 \pi \mu D_{p}} & \begin{array}{c}
m_{0}-\text { massa do líquido deslocado } \\
w-\text { velocidade angular } \\
r-\text { distancia ao centro da centrífuga } \\
C c-\text { fator de escorregamento }
\end{array}
\end{array}
$$

\subsection{Equação de Lamm}

A partir das informações prévias, é possível modelar o perfil de concentração de nanopartículas em função do tempo e do raio da centrífuga, considerando que não há convecção do fluido na cela centrífuga, conforme a equação diferencial (4). A nomenclatura é apresentada no final do trabalho.

$$
\frac{\partial C}{\partial t}+\vec{V} \cdot g r \vec{a} d C=\operatorname{div}(\operatorname{Dgra} \vec{a} d C)-\operatorname{div}(\vec{v} C)
$$

Escrevendo radialmente a equação (4), chega-se à Equação de Lamm: 


$$
\begin{array}{l|l|l|l|}
\hline \frac{\partial C}{\partial t}=\frac{1}{r} \frac{\partial}{\partial r}\left[\mathrm{rD} \frac{\partial C}{\partial r}-s w^{2} r C\right] & \\
D=\frac{k T C_{c}}{3 \pi \mu D_{p}} \longleftrightarrow & S=\frac{v}{w^{2} r}=\frac{\left(m-m_{0}\right)}{3 \pi \mu D_{p}} \\
\text { Coeficiente Svedberg }
\end{array}
$$

Com as seguintes condições de contorno (C.C.):

C.C. inicial: $\quad t=0 \quad ; \quad C=C_{0} \quad ; \quad r_{0}<r<r_{b}$

C.C no menisco: $t>0 \quad ; D \frac{\partial C}{\partial r}=r w^{2} s C ; r=r_{0}$

C.C. no fundo: $\quad t>0 \quad ; D \frac{\partial C}{\partial r}=r w^{2} s C ; r=r_{b}$

\subsection{Solução Analítica}

Soluções analíticas fechadas para a equação do transporte de Lamm não são disponíveis dentro das condições de contorno requeridas (Behlke, J; Ristau, O., 1997). No entanto, nos anos sessenta, Fujita desenvolveu algumas soluções aproximadas (Fujita 1962), entre as quais a equação (6).

$$
C=\frac{C_{0}}{2} e^{-\tau}\left\{\begin{array}{l}
2-\operatorname{erfc}\left(\frac{z-\tau \alpha}{2 \sqrt{a e \tau}}\right)-\frac{a}{e} \exp \left(\frac{z \alpha}{a e}\right) \operatorname{erfc}\left(\frac{\tau \alpha+z}{2 \sqrt{a e \tau}}\right)+\frac{\gamma}{e} \exp \left(\frac{e \tau+z}{e}\right) \operatorname{erfc}\left(\frac{\tau \gamma+z}{2 \sqrt{a e \tau}}\right) \\
-\operatorname{erfc}\left(\frac{1-z+\alpha \tau}{2 \sqrt{a e \tau}}\right)-\frac{a}{e} \exp \left(\frac{-\alpha(1-z)}{a e}\right) \operatorname{erfc}\left(\frac{1-z-\alpha \tau}{2 \sqrt{a e \tau}}\right) \\
+\frac{\gamma}{e} \exp \left(\frac{e \tau-1+z}{e}\right) \operatorname{erfc}\left(\frac{1-z-\gamma \tau}{2 \sqrt{a e \tau}}\right)
\end{array}\right\}
$$

\section{METODOLOGIA EXPERIMENTAL}

Para síntese das AgNPs, foi utilizado o método de Turkevich adaptado para prata, que se mostrou vantajoso por sua rapidez, custo baixo, reprodutibilidade boa e não ser tóxico ao ser humano nem ao meio ambiente (Oliveira, R., 2013). Neste, o íon de prata é reduzido pelo citrato de sódio.

Basicamente, para a síntese de AgNPs coloca-se 0,5L de água mili-Q em um cristalizador encamisado, liga-se um agitador a $1000 \mathrm{RPM}$ e aquece-se a $90^{\circ} \mathrm{C}$. Nessa temperatura, coloca-se 90 $\mathrm{mg}$ de nitrato de prata e em seguida goteja-se $10 \mathrm{ml}$ de uma solução aquosa $1 \%$ mássica de Citrato de 
Sódio com uma bomba peristáltica. Após 20 minutos de reação, retira-se a solução do reator e deixase resfriar a temperatura ambiente.

Amostras dessa dispersão de $1,5 \mathrm{ml}$ são centrifugadas em variadas rotações, retirando-se alíquotas do sobrenadante de $15 \mathrm{em} 15$ minutos para caracterização. Essas alíquotas são caracterizadas por DLS e comparadas com a solução antes da centrifugação e também com o modelo proposto.

\section{RESULTADOS E DISCUSSÃO}

O modelo matemático revela que as partículas de maiores tamanhos sedimentam mais rápido que as menores conforme FIGURA 2 para uma rotação de 5000 RPM. Partículas de menores tamanhos sedimentam de forma mais lenta devido à menor massa e a uma maior influência da difusividade browniana, ao contrário das maiores AgNPs onde o efeito da força centrífuga prevalece.
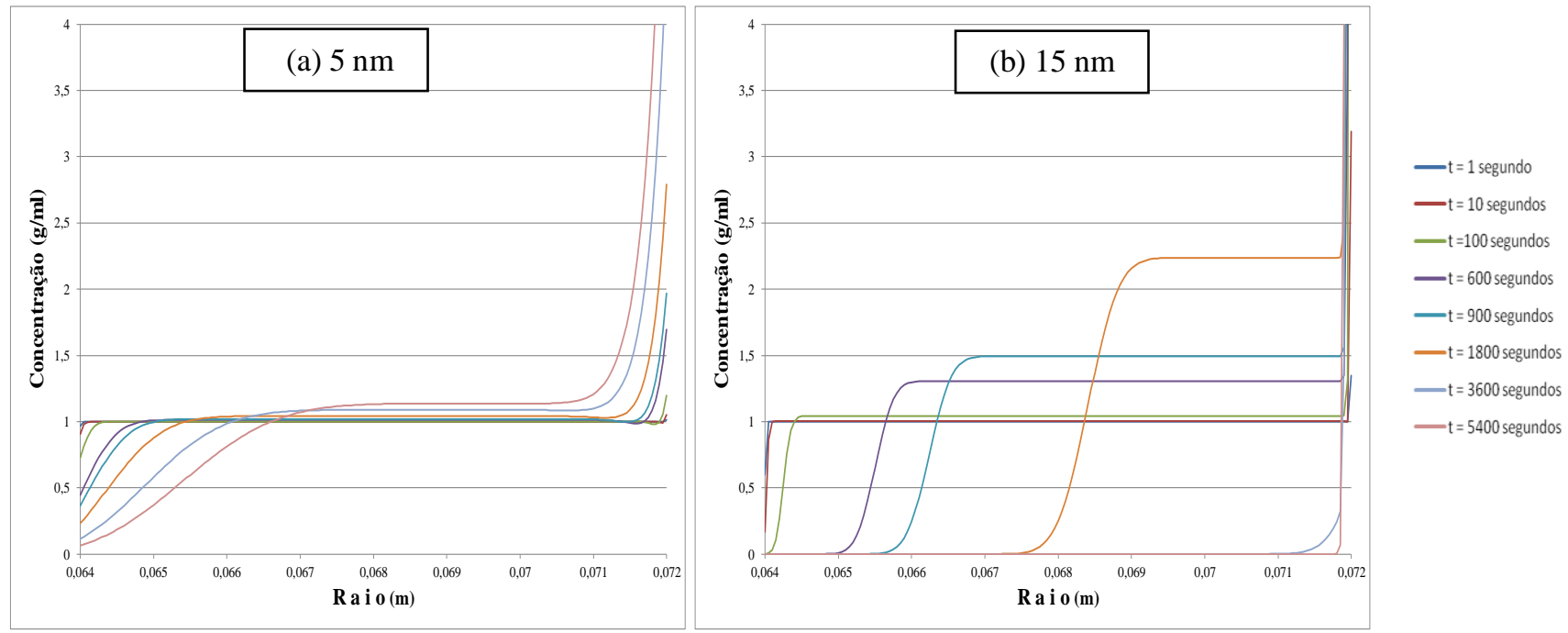

Figura 2- Distribuição da concentração radial calculada pela equação (6) para AgNPs de diferentes tamanhos ((a) 5 e (b) $15 \mathrm{~nm}$ ) sob rotação de 5000 RPM . A simulação foi obtida para concentrações iniciais $C_{0}=0,998, T=22^{\circ}$ C, difusividade browniana estimada (a) $D=9,27 \mathrm{E}-11 \mathrm{~m}^{2} / \mathrm{s}$ e (b) $\mathrm{D}=3,09 \mathrm{E}-11 \mathrm{~m}^{2} / \mathrm{s}$ e coeficiente de Svedberg (a) $\mathrm{s}=$ $141,5 \mathrm{~S}$ e (b) $s=1273,7 \mathrm{~S}$.

O modelo também permite simular o comportamento da sedimentação em função de diferentes intensidades de rotação, conforme FIGURA 3. Para partículas de um mesmo tamanho (no exemplo, de $5 \mathrm{~nm}$ ) observa-se que a sedimentação é mais rápida no mesmo sentido da intensidade de rotação, conforme esperado. 


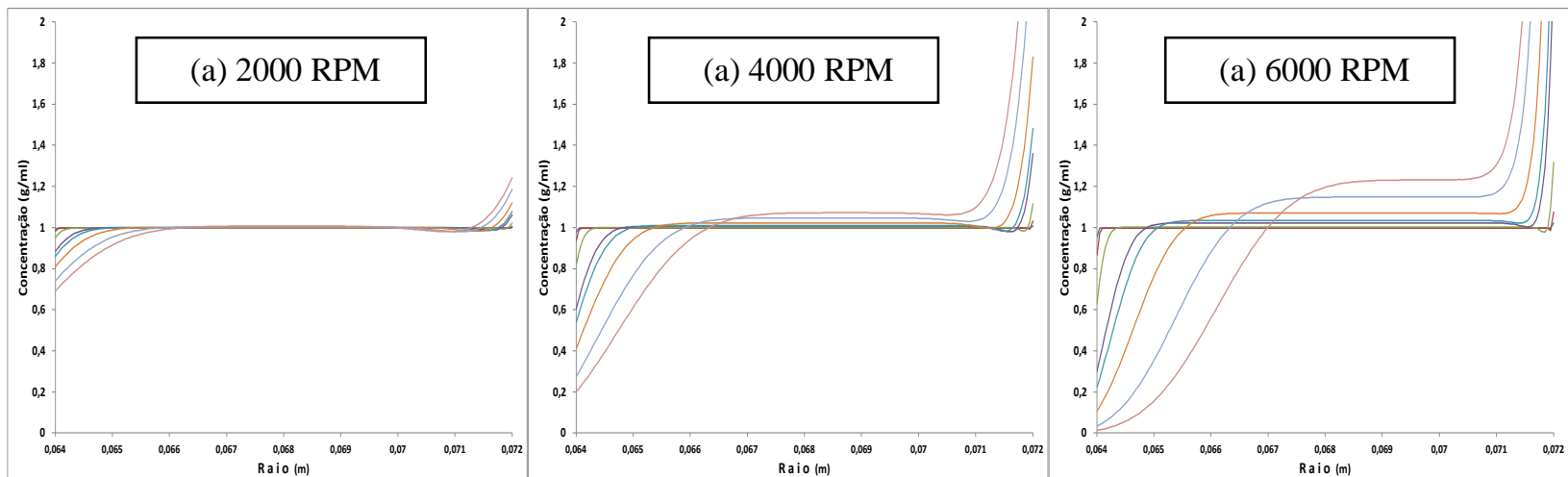

Figura 3 - Distribuição da concentração radial calculada pela equação (6) para AgNPs de tamanho 5 nm sob rotações de (a) 2000, (b) 4000 e (c) 6000 RPM . A simulação foi obtida para concentrações iniciais $\mathrm{C}_{0}=0,998, T=$ $22^{\circ} \mathrm{C}$, difusividade browniana estimada $\mathrm{D}=9,27 \mathrm{E}-11 \mathrm{~m}^{2} / \mathrm{s}$ e coeficiente de $\mathrm{Svedberg} \mathrm{s}=141,5 \mathrm{~S}$.

Com a simulação foi possível quantificar variáveis de separação como taxa e tempo de rotação em uma centrífuga. Nota-se que centrífugas comuns são capazes de sedimentar as AgNPs na faixa de tamanho entre 5 e $15 \mathrm{~nm}$, uma vez que a densidade da prata é bastante superior à do meio aquoso.

Para avaliar o desempenho desse método de separação, AgNPs foram sintetizadas e centrifugadas. Alíquotas de seu sobrenadante analisadas a cada 15 minutos sob centrífuga (EPPENDORF Centrifuge 5415R) a 5000 RPM e temperatura de $22^{\circ} \mathrm{C}$. As alíquotas foram posteriormente caracterizadas por DLS (COULTER N4 Plus Submicron Particle Size Analysis).

Conforme TABELA 3, os tamanhos médios das AgNPs diminuiram conforme aumentava o tempo de centrifugação, indicando que menores tamanhos podem ser obtidos com esse processo póssíntese, conforme previa o modelo.

Tabela 3 - Tamanhos das partículas nos sobrenadantes por DLS para tamanho médio e desvio padrão em diferentes tempos de centrifugação a $5000 \mathrm{RPM}$ e $22^{\circ} \mathrm{C}$.

\begin{tabular}{ccc}
\hline $\begin{array}{c}\text { Tempo de Centrifugação } \\
\text { (minutos) }\end{array}$ & Tamanho médio (nm) & Desvio Padrão (nm) \\
\hline 0 & 52,49 & 25,25 \\
15 & 36,15 & 27,49 \\
30 & 28,54 & 16,99 \\
45 & 13,03 & 19,08 \\
60 & 2,00 & 0,00 \\
\hline
\end{tabular}

\section{CONCLUSÕES}

A centrifugação de nanopartículas de prata em meio aquoso foi estudada teoricamente. A difusão molecular retarda o processo, mas devido à alta densidade da prata, uma separação granulométrica eficiente é possível com rotações moderadas. Tais previsões do modelo foram confirmadas experimentalmente pela possibilidade de separar completamente nanopartículas com 
tamanhos entre 2 e $50 \mathrm{~nm}$. Conclui-se que a centrifugação é um método eficiente, simples e rápido para esse tipo de separação. Os resultados desse estudo não se restringem a nanopartículas de prata, mas estendem-se para a centrifugação de outros tipos de nanopartículas.

\section{NOMENCLATURA}

$C$ - Concentração de nanopartículas $(\mathrm{g} / \mathrm{mL})$

$C_{0}$ - Concentração inicial de nanopartículas $(\mathrm{g} / \mathrm{mL})$

$r$ - Posição da seção da cela centrífuga (m)

$r_{0}$ - Posição do menisco (m)

$r_{b}$ - Posição do fundo da cela $(\mathrm{m})$

$s$ - Coeficiente de Sedimentação Svedberg (s)

$D$ - Coeficiente de Difusividade Browniana

$t$ - Tempo de centrifugação

Adimensionais

$$
\begin{aligned}
& \tau=2 s w^{2} t ; x=\left(\frac{r}{r_{0}}\right)^{2} ; x_{b}=\left(\frac{r_{b}}{r_{0}}\right)^{2} ; \varepsilon=\frac{2 D}{s w^{2} r_{0}^{2}} ; z=\frac{x-1}{x_{b}-1} ; e=\frac{\varepsilon}{x_{b}-1} ; a=\frac{1+x_{b}}{2\left(x_{b}-1\right)} \\
& \alpha=a-e ; \gamma=a+e
\end{aligned}
$$

\section{REFERÊNCIAS}

SANTOS, C. A et al. Antimicrobial effectiveness of silver nanoparticles co-stabilized by bioactive copolymer pluronic F68. Journal of Nanobiotechnology, 2012,10:13.

LIU, J. et al. Methods for separation, identification, characterization and quantification of silver nanoparticles. Trends in Analytical Chemestry, Vol. 33, 2012.

BEHLKE, J; RISTAU, O. An improved approximate solution of the Lamm equation for the simultaneous estimation of sedimentation and diffusion coefficients from sedimentation velocity experiments. Biophysical Chemistry, 1997. 
OLIVEIRA, R. Síntese de nanopartículas de prata usando citrato de sódio, 2013.

MARTINÉZ-CASTAÑÓN, G.A. et al. Synthesis and antibacterial activity of silver nanoparticles with diferent sizes. J Nanopart Res, 2008.

SHARMA, V. et al. Shape separation of gold nanorods using centrifugation. PNAS, 2009.

FRIEDLANDER, S. K. Smoke, Dust and Haze: Fundamentals of Aerosol Dynamics. New York: Oxford University Press, 2000.

LI, S. et al. Separation of Gold nanorods using gradient ultracentrifugation. Nano Res., 2011.

BAKER, C. et al. Synthesis and antibacterial properties of silver nanoparticles. J Nanosci Nanotechnol, 2005.

MARAMBIO-JONES, C.; HOEK, E. M. V. A review of the antibacterial effects of silver nanoparticles and potential implication for human health and the environment. J Nanopart Res, 2010. 